\title{
PENGARUH FASE APILL PADA SIMPANG TERHADAP PERILAKU MENUNGGU PENGGUNA SEPEDA MOTOR DI KOTA TEGAL
}

\author{
Arga Dwiyantara \\ D IV Manajemen Keselamatan \\ Transportasi Jalan \\ Politeknik Keselamatan \\ Transportasi Jalan \\ Jalan Perintis Kemerdekaan \\ No. 3 Kota Tegal \\ blorapunya5@gmail.com
}

\author{
Heni Putri \\ Pramudyawardani \\ D IV Manajemen \\ Keselamatan Transportasi \\ Jalan \\ Politeknik Keselamatan \\ Transportasi Jalan \\ Jalan Perintis Kemerdekaan \\ No. 3 Kota Tegal \\ putriheni12@gmail.com
}

\author{
Muhammad Rikzam \\ Kamal \\ D IV Manajemen \\ Keselamatan Transportasi \\ Jalan \\ Politeknik Keselamatan \\ Transportasi Jalan \\ Jalan Perintis Kemerdekaan \\ No. 3 Kota Tegal \\ mrikzamk@gmail.com
}

\begin{abstract}
Intersection is a critical area on a highway where a point of conflict and where bottlenecks due to the merging of two or more roads. The junction arrangements that do not fit will cause traffic problems, particularly the intersection you have installed APILL. Violations often occur are agresive driving behavior in the form of the behavior of the wait. Based on existing conditions, the behavior of waiting that occurred at an intersection with two and four phase settings have a difference. Violations committed by users i.e. a motorcycle broke through APILL, stop at the stop line and the opposing lanes consuming. APILL phase setting should resolve the problems of the particular behavior of the wait. Methods of analysis used i.e. the dependent samples T-test test with SPSS 16.0 program use. Based on the current test sig (2-tailed) of $>0.050 .628$ then it can be concluded that there was no significant difference between the behavior of waiting at an intersection that has a setting of two and four phases.
\end{abstract}

Keywords : Agresive Driving, APILL, the dependent sample T test, Intersection, SPSS

\begin{abstract}
Abstrak
Simpang adalah suatu area yang kritis pada suatu jalan raya yang merupakan tempat titik konflik dan tempat kemacetan karena bertemunya dua ruas jalan atau lebih. Pengaturan simpang yang tidak sesuai akan menimbulkan masalah lalu lintas, khususnya simpang yang telah dipasang APILL. Pelanggaran yang sering terjadi adalah perilaku agresive driving berupa perilaku menunggu. Berdasarkan kondisi eksisting, perilaku menunggu yang terjadi pada simpang dengan dua dan empat fase pengaturan memiliki perbedaan. Pelanggaran yang dilakukan oleh pengguna sepeda motor yaitu menerobos APILL, berhenti di stop line dan memakan lajur lawan. Seharusnya pengaturan fase APILL dapat mengatsi permasalahan khususnya perilaku menunggu. Metode analisis yang digunakan yaitu uji dependen sample $T$ test dengan menggukan program SPSS 16.0. Berdasarkan nilai uji sig. (2-tailed) sebesar 0,628 > 0,05 maka dapat disimpulkan bahwa tidak terdapat perbedaan yang signifikan antara perilaku menunggu pada simpang yang memiliki pengaturan dua dan empat fase.
\end{abstract}

Kata Kunci : Agresive Driving, APILL, dependen sample $T$ test, Simpang, SPSS

\section{PENDAHULUAN}

Simpang adalah suatu area yang kritis pada suatu jalan raya yang merupakan tempat titik konflik dan tempat kemacetan karena bertemunya dua ruas jalan atau lebih (Pignataro, 1973). Karena merupakan tempat terjadinya konflik dan kemacetan maka hampir semua simpang terutama di perkotaan membutuhkan pengaturan. Pengaturan pada daerah simpang ini, guna menghindari dan meminimalisir terjadinya konflik dan beberap permasalahan yang mungkin timbul di daerah persimpangan ini.

Pengaturan pada simpang dapat dilakukan dengan memasang apill maupun 
membuat bundaran pada simpang.

Sebanyak 2.943 kendaraan bermotor atau 49 unit per menit tercatat keluar dari Kota Tegal. Jumlah kendaraan bermotor yang keluar ke Kota Tegal mendominasi atau lebih banyak

15.042 unit. Kepala Dinas Perhubungan Komunikasi dan Informatika Kota Tegal, Khaerul Huda menjelaskan, tercatat sebanyak 35.322 unit kendaraan bermotor keluar dari Kota Tegal menuju arah Jakarta. Dari jumlah itu, sebanyak 61 persen atau 21.577 unit adalah sepeda motor. Untuk mobil pribadi, tercatat sebanyak 10.554 unit. Untuk jumlah angkutan yang lewat sebanyak 81 unit. Sementara bus sedang sebanyak 433 unit dan bus besar sebanyak 448 unit. Sedangkan truk kecil sebanyak 726 unit dan truk sedang sebanyak 799 unit serta kontainer sebanyak 538 unit. Dan, untuk kendaraan tak bermotor sebanyak 166 unit.

Dengan Besarnya jumlah pengguna sepeda motor yang ada pada kota Tegal maka akan menimbulkan juga masalah lalu lintas. Terlebih lagi masalah tersebut akan terjadi pada persimpangan. Pengaturan simpang yang tidak sesuai akan menimbulkan masalah lalu lintas khususnya simpang yang telah dipasang APILL. Pengguna sepeda motor akan melakukan pelanggaran pada simpang tersebut dengan melakukan perilaku agresive driving. Para pengguna sepeda motor akan melalukan perilaku menerobos maupun menunggu kendaraan yang tidak sesuai pada saat lampu merah. Para pengguna kendaraan sepeda motor akan mencoba untuk melewati simpang tersebut dengan cepat apalagi jika pengaturan fase pada simpang tersebut semakin sedikit.

Seharusnya pengaturan APILL yang dipasang itu berfungsi untuk mengurangi masalah lalu lintas yang ada pada simpang tersebut. pengaturan APILL yang tepat akan mengurangi tindak pelangggaran pengguna jalan yang melintasi simpang tersebut. pengguna jalan yang tertib akan menciptakan kondisi lalu lintas yang lancar, aman dan selamat. pada dasarnya tidak hanya dari pengaturan simpang, etika dan perilaku serta kesadaran dari semua pengguna jalan untuk menaati peraturan merupakan faktor terpenting untuk menciptakan lalu lintas yang aman dan selamat. oleh sebab itu dalam penelitian ini akan membahas tentang Pengaruh Fase APILL pada Simpang terhadap Perilaku Mengemudi Pengguna Sepeda Motor Di Kota Tegal.

Berdasarkan uraian latar belakang di atas, maka tujuan dari penelitian ini yaitu Mengetahui apakah terdapat perbedaan tingkat agresive driving pada persimpangan berapill berdasarkan jenis fase. Mengetahui perilaku menunggu pengemudi sepeda motor berdasarkan jenis fase APILL di kota Tegal.

\section{TINJAUAN PUSTAKA}

\section{Pengertian Simpang}

Menurut Peraturan Pemerintah Nomor 43 Tahun 1993 Tentang Prasarana dan Lalu Lintas Jalan, persimpangan adalah pertemuan atau percabangan jalan, baik sebidang maupun yang tidak sebidang. Termasuk dalam pengertian persimpangan adalah pertigaan (simpang tiga), perempatan (simpang empat), perlimaan (simpang lima), persimpangan bentuk bundaran, dan persimpangan tidak sebidang, namun tidak termasuk persilangan sebidang dengan rel kereta api. 


\section{Jenis Simpang}

Menurut Direktorat Jendral Bina Marga dalam Manual Kapasitas Jalan Indonesia (1997), pemilihan jenis simpang untuk suatu daerah sebaiknya berdasarkan pertimbangan ekonomi, pertimbangan keselamatan lalu lintas, dan pertimbangan lingkungan Menurut Morlok(1988), jenis simpang berdasarkan cara pengaturannya dapat dikelompokkan menjadi2 (dua) :

1. Simpang jalan tanpa sinyal, yaitu simpang yang tidak memakai sinyal lalu lintas. Pada simpang ini pemakai jalan harus memutuskan apakah mereka cukup aman untuk melewati simpang atau harus berhenti dahulu sebelum melewati simpang tersebut,

2. Simpang jalan dengan sinyal, yaitu pemakai jalan dapat melewati simpangsesuai dengan pengoperasian sinyal lalu lintas. Jadi pemakai jalan hanya boleh lewat pada saat sinyal lalu lintas menunjukkan warna hijau pada lengan simpangnya.

\section{Fase Sinyal}

Pemilihan fase pergerakan tergantung dari banyaknya konflik utama, yaitu konflik yang terjadi pada volume kendaraan yang cukup besar. Menurut MKJI, 1997 Jika fase sinyal tidak diketahui, maka pengaturan dengan dua fase sebaiknya digunakan sebagai kasus dasar. Pemisahan gerakan-gerakan belok kanan biasanya hanya dilakukan berdasarkan pertimbangan kapasitas kalau gerakan membelok melebihi $200 \mathrm{smp} / \mathrm{jam}$

\section{Pengertian Agresive Driving}

Baron dan Richardson 1994) dalam (Anderson \& Bushman, 2002) menyatakan bahwa aggressive adalah segala bentuk perilaku yang dimaksudkan untuk melukai atau menyakiti makluk hidup lain yang terdorong untuk menghindari perlakuan itu. Aggressive driving merupakan pola disfungsi dari perilaku sosial yang mengganggu keamanan publik.Aggressive driving dapat melibatkan berbagai perilaku yang berbeda termasuk perilaku menerobos, mengklakson, menambah kecepatan kendaraan, berhenti melebihi garis zebra Cross, melebihi batas marka tengah jalan di suasana lalu lintas tenang (Houston, Harris, \& Norman 2003). Menurut Tasca (2000) suatu perilaku mengemudi dikatakan agresifjika dilakukan secara sengaja, cenderung meningkatkan resiko tabrakan dan dimotivasi oleh ketidaksadaran, permusuhan, dan atau upaya untuk mengemat waktu. Menurut (James \& Nahl, 2000) mengemudi agresif adalah mengemudi di bawah pengaruh gangguan emosi, menghasilkan tingkah laku yang memaksakan sesuatu yang sangat resiko pada pengemudi lain.

\section{Jenis-jenis Agresive Driving}

James \& Nahl (2000) membagi perilaku aggressive driving menjadi beberapa kategori yaitu :

Kategori I: Impatience (ketidaksabaran) intentievenness (ketidak perhatian)

a. Menerobos lampu merah.

b. Menambah kecepatan ketika melihat lampu kuning.

c. Posisi kendaraan saat menunggu di apill berada pada lajur tunggu belok kiri.

d. Kendaraan berada melebihi garis henti pada zebra cross

e. Posisi kendaraan pada saat menunggu berada pada jalur yang salah dan melebihi batas marka tengah jalan

f. Tidak memberikan tanda ketika dibutuhkan seperti berbelok/berhenti. 
g. Menambah/mengurangi kecepatan secara mendadak.

Kategori II: Power strungle (adu kecepatan)

a. Mengalangi orang yang akan berpindah jalur, menolak untuk memberi jalan atau pindah

b. Mengancam atau memancing kemarahan pengemudi lain dengan berteriak, membuat gerakan-gerakan yang memancing kemarahan dan membunyikan klakson berkali-kali.

c. Mengerem secara mendadak untuk menyerang atau membalas pengemudi lain.

\section{METODOLOGI}

Alur penelitian ini dapat digambarkan dalam bagan alir dibawah ini :

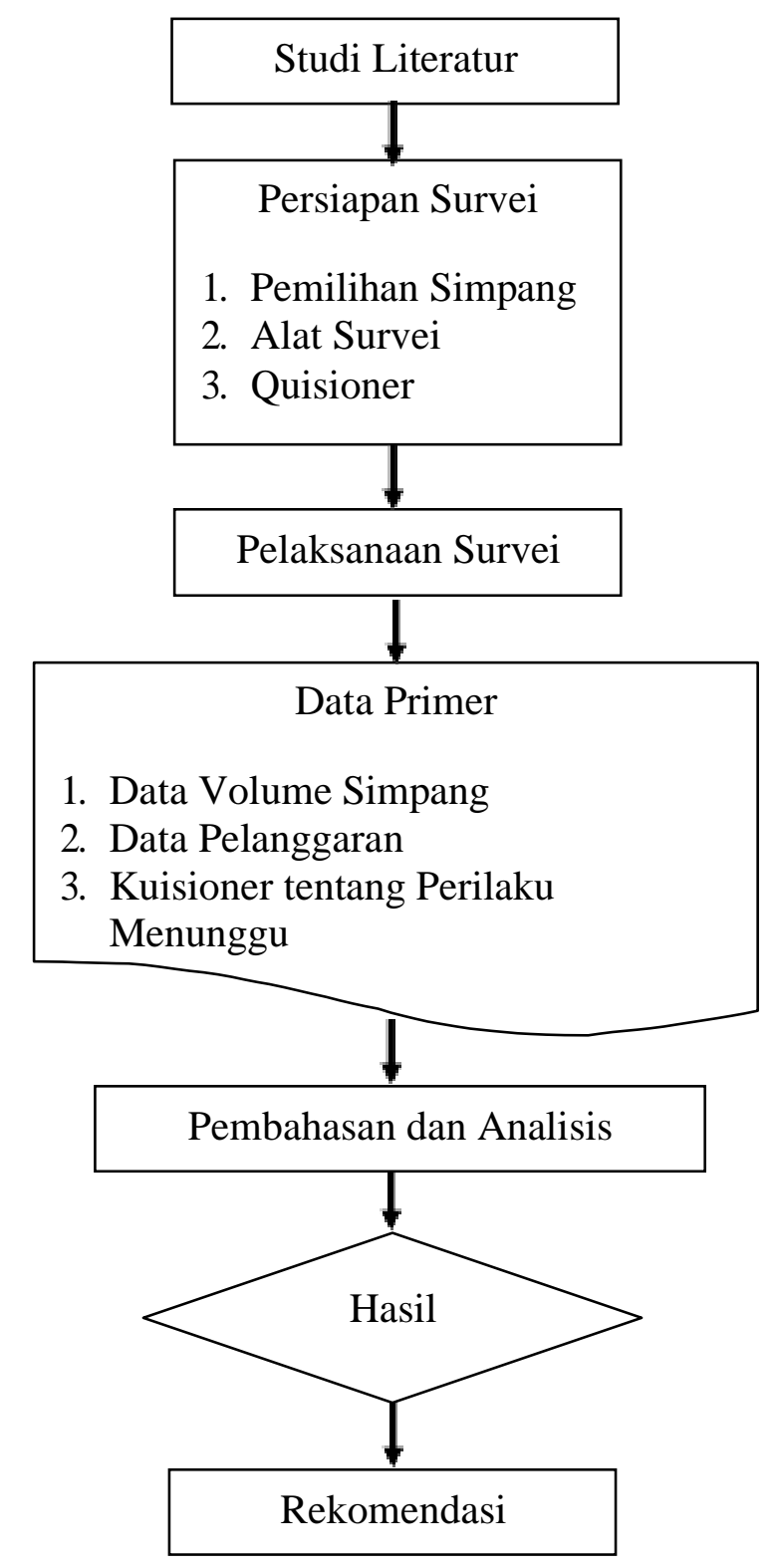

Gambar 1. Bagan Alir Penelitian 
Penelitian ini termasuk penelitian yang menggunakan pendekatan kuantitatif karena data atau informasinya dianalisis menggunakan teknik statistik. Lokasi penelitian terletak pada simpang empat kota Tegal yang memiliki 2 fase dan 4 fase. Simpang yang memiliki 2 fase yaiyu simpang Kardinah dan yang memiliki 4 fase yaitu simpang Alun-alun. Sumber data yang diperoleh dalam penelitian ini adalah data primer yakni data yang diperoleh secara autentik, langsung dicari dan diterima oleh peneliti melalui teknik observasi langsung dan kuisioner. Sebelum melaksanakan pembagian kuisioner, dilakukan penentuan populasi dan sampel dengan menggunakan rumus Slovin (Sevilla et. al., 1963). populasi dan sampel yang digunakan yaitu taruna remaja PKTJ yang berdomisili di Tegal. Metode analisis yang digunakan yaitu uji dependen sample $T$ test dengan menggukan program SPSS 16.0.

\section{HASIL DAN PEMBAHASAN}

\section{Lokasi Penelitian}

Lokasi penelitian terletak pada simpang empat kota Tegal yang memiliki 2 fase dan 4 fase. Simpang yang memiliki 2 fase yaitu simpang Kardinah dan yang memiliki 4 fase yaitu simpang Alun-alun.

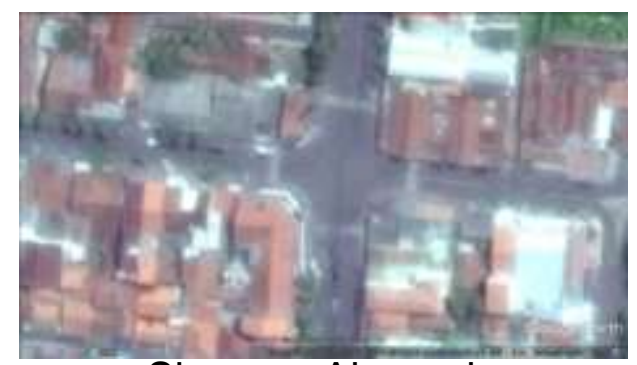

Simpang Alun - alun

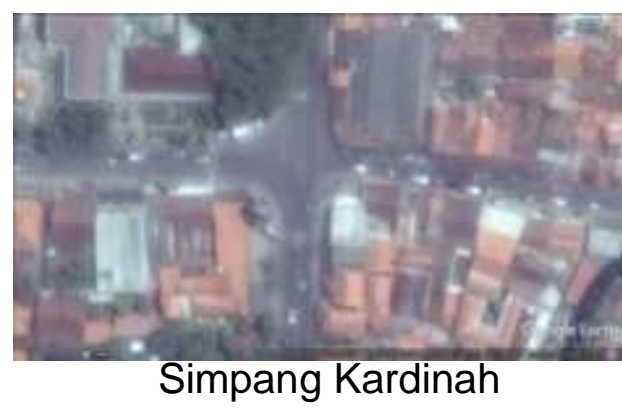

Simpang Kardinah

Gambar 2. Lokasi penelitian

\section{Jumlah Pelanggaran}

Tabel 1. Jenis Pelanggaran di masing-masing Simpang

\begin{tabular}{|r|l|c|c|c|}
\hline \multirow{2}{*}{ No } & \multirow{2}{*}{ Simpang } & \multicolumn{3}{|c|}{$\begin{array}{c}\text { Pelanggara } \\
n\end{array}$} \\
\cline { 3 - 5 } & Menerobos & $\begin{array}{l}\text { Berhenti } \\
\text { di } \\
\text { stopline }\end{array}$ & $\begin{array}{l}\text { Memakan } \\
\text { Lalur } \\
\text { Lawan }\end{array}$ \\
\hline 1 & Alun-alun & 122 & 28 & 370 \\
\hline 2 & Kardinah & 446 & 120 & 770 \\
\hline
\end{tabular}

\section{Uji Validitas}

Untuk melakukan uji validitas ini menggunakan program SPSS. Teknik pengujian yang sering digunakan para peneliti untuk uji validitas adalah menggunakan korelasi Bivariate Pearson (Produk Momen Pearson). Analisis ini dengan cara mengkorelasikan masing- masing skor item dengan skor total. 


\begin{tabular}{|c|c|c|c|c|c|c|c|c|c|c|c|c|c|c|}
\hline \multicolumn{15}{|c|}{ Imter-teen Corretation matrix } \\
\hline & soal1 & Soal2 & $80 a n$ & Sorat & Paals & Boalf & Saal7 & SoalB & Bogig & Soalio & Boali1 & Boal12 & Soal13 & Total \\
\hline 8oat & 1.000 & 123 & 081 & 094 & .155 & 365 & 135 & 071 & 091 & 166 & 017 & $=093$ & 103 & 303 \\
\hline 80812 & 123 & 1.000 & .216 & 488 & .155 & 236 & 218 & 307 & 165 & 440 & 067 & .198 & 373 & 581 \\
\hline Boal3 & 061 & 296 & 1.000 & .162 & .363 & 307 & 944 & .349 & .029 & .244 & 144 & 430 & 367 & 686 \\
\hline Soal4 & .094 & 468 & 152 & 1000 & .051 & 327 & 110 & 230 & 609 & 830 & 024 & .090 & 218 & 610 \\
\hline 8oals & 155 & 155 & 363 & DSt & 1.000 & 152 & 346 & 188 & .217 & org & 143 & .272 & 442 & .456 \\
\hline Soal6 & 365 & 236 & 307 & 327 & .152 & 1000 & 326 & 243 & 435 & .020 & -141 & .096 & 381 & .463 \\
\hline Soaly & 135 & 218 & .944 & 110 & 346 & $n 6$ & 1.000 & 357 & .006 & 217 & .113 & 353 & 401 & 676 \\
\hline Boa18 & or1 & $30 \%$ & .349 & 230 & .186 & 243 & 367 & 1.000 & .050 & 162 & 168 & 580 & 311 & 589 \\
\hline Soals & 081 & 145 & -029 & 609 & -217 & 435 & -006 & 050 & 1000 & 318 & -006 & -038 & -033 & 329 \\
\hline Boal10 & 166 & 440 & 244 & 630 & 079 & $020^{\circ}$ & 217 & 162 & 318 & 1000 & 170 & 248 & 153 & 606 \\
\hline Boalt1 & 017 & 067 & 144 & 024 & .149 & -141 & 113 & 166 & -006 & 170 & 1000 & 353 & -066 & 322 \\
\hline Soalt2 & -093 & .198 & 430 & .090 & 272 & -056 & 353 & 580 & $-03 B$ & 249 & 352 & 1.000 & 272 & 549 \\
\hline Soanz & 103 & 373 & $.36 ?$ & 218 & .442 & 301 & $40 t$ & 311 & -033 & .153 & -066 & .272 & 1.000 & 556 \\
\hline Total & 203 & 591 & .608 & .610 & .456 & 463 & 876 & 689 & 329 & 606 & 222 & 549 & 556 & 1.000 \\
\hline
\end{tabular}

\section{Gambar 3. Uji Validitas Simpang Kardinah}

\begin{tabular}{|c|c|c|c|c|c|c|c|c|c|c|c|c|c|c|}
\hline & Soali & $80 a 12$ & Soal3 & 80214 & Soals & Boalif & Soal7 & Boals. & Soaig & Borito & soall1 & Soail12 & Soas13 & Total \\
\hline Soat1 & 1000 & 006 & 000 & .095 & 393 & 118 & 142 & .109 & 015 & .103 & .070 & 004 & 096 & 333 \\
\hline Soat2 & 1006 & 1000 & 290 & .396 & 164 & 121 & 123 & .238 & 057 & 320 & 160 & 304 & $43 ?$ & .577 \\
\hline Boal3 & 000 & 298 & 1.000 & -030 & 083 & 212 & 135 & 916 & -130 & $.07 t$ & 022 & 614 & 211 & 511 \\
\hline Soal4 & cas & 338 & .033 & 1.000 & 261 & 023 & 071 & .015 & 448 & 37 & $\therefore 093$ & ort & 03? & .449 \\
\hline Soals & 333 & 164 & .883 & 281 & 1000 & cos & 448 & 139 & .083 & $=007$ & a96 & 170 & 299 & 467 \\
\hline Soal6 & 118 & 121 & 212 & 023 & oeg & 1000 & 407 & .231 & 324 & .082 & 033 & 433 & 297 & 465 \\
\hline Soal? & 142 & 122 & .135 & ors & 446 & 407 & 1000 & .237 & .154 & 217 & 143 & 413 & 379 & .590 \\
\hline Boals & 109 & .238 & 916 & -015 & 139 & 231 & 237 & 1.000 & .020 & .011 & 054 & 6et & 259 & .565 \\
\hline Boah & 015 & 057 & -130 & 448 & -083 & 334 & 151 & 020 & 1000 & 277 & 029 & 141 & 051 & .374 \\
\hline Soalto & 103 & 320 & 071 & 317 & -007 & $\cos 2$ & 217 & -011 & 277 & 1000 & 074 & 221 & 268 & 497 \\
\hline Boalt1 & 970 & 160 & 022 & -093 & 096 & 033 & 143 & 054 & 028 & .074 & 1.000 & 2725 & 1.49 & .310 \\
\hline Soalt? & $\mathrm{COH}$ & 304 & 814 & ent & 170 & 133 & 413 & 6594 & 141 & 221 & 225 & 1000 & 404 & F99 \\
\hline Sogh13 & 066 & .437 & 211 & 097 & 299 & 297 & 379 & .259 & .051 & .208 & 149 & 404 & $t .000$ & 597 \\
\hline Total & 203 & 577 & 511 & 449 & 467 & 485 & 690 & .566 & 374 & 497 & 310 & 899 & $69 ?$ & 1.000 \\
\hline
\end{tabular}

Gambar 4. Uji Validitas Simpang Alun-alun

Dari hasil uji validitas semua item kuisioner memiliki hasil yang valid karena nilai $r$ hitung $>r$ tabel.

$$
\begin{aligned}
\text { dimana }: \text { df } & =\mathrm{N}-2 & & (\mathrm{~N}=45) \\
& =45-2 & & \\
& =43 & & \text { (tabel } r \text { statistika, df } 43=0,294)
\end{aligned}
$$

\section{Uji Reliabilitas}

Berdasarkan Uji reabilitas dapar diketahui bahwa nilai dari Cronbanch's Alpha adalah 0,720. Dengan demikian dapat diketahui bahwa data penelitian bersifat reliable.

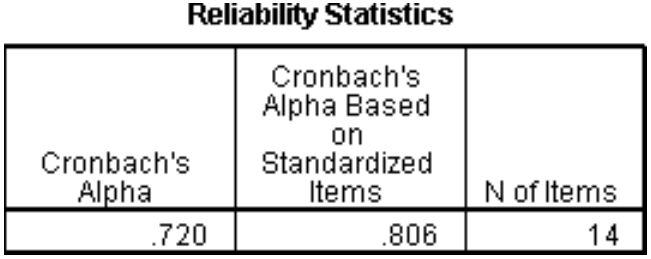

\begin{tabular}{|c|c|c|}
\hline $\begin{array}{c}\text { Cronbach's } \\
\text { Alpha }\end{array}$ & $\begin{array}{c}\text { Cronbach's } \\
\text { Alpha Based } \\
\text { on } \\
\text { Standardized } \\
\text { Items } \\
\end{array}$ & N of Items \\
\hline .731 & .826 & 14 \\
\hline
\end{tabular}

Simpang Alun - alun
Reliability Statistics

Simpang Kardinah

Gambar 5. Uji Reabilitas dengan SPSS 16.0 


\section{Uji Normalitas}

Uji normalitas merupakan salah satu uji mendasar yang dilakukan sebelum melakukan analisis data lebih lanjut atau lebih dalam, data yang normal sering dijadikan landasan dalam beberapa uji statistik. Dalam penelitian ini menggunakan teknik Kolmogorov- Smirnov dikarenakan jumlah data lebih dari 50.

\begin{tabular}{|c|c|c|c|c|c|c|c|}
\hline & \multirow[b]{2}{*}{ Fase } & \multicolumn{3}{|c|}{ Kolmogorov-Smirnove } & \multicolumn{3}{|c|}{ Shapiro-Wilk } \\
\hline & & Statistic & $\mathrm{df}$ & Siq. & Statistic & $\mathrm{df}$ & Siq. \\
\hline \multirow[t]{2}{*}{ Jumlah } & 2 & .127 & 45 & .065 & .963 & 45 & .164 \\
\hline & 4 & .127 & 45 & .065 & .963 & 45 & .164 \\
\hline
\end{tabular}

a. Lilliefors Sianificance Correction

Gambar 6. Hasil Uji Normalitas dengan SPSS 16.0

Berdasarkan analisis Kormogrov-Simirnov diatas dapat di jelaskan sebagai

berikut :

1. Hipotesis

$\mathrm{HO}=$ Populasi distribusi normal

$\mathrm{H} 1 \quad=$ Populasi tidak berdistribusi normal

2. Tingkat

Signifikansi $\alpha=$

$5 \%$

3. Daerah kritis

Jika Signifikan $\leq \alpha$ : Tolak HO

4. Statistik Uji

Sig. 2 fase $\quad=0,065>\alpha=0,05$

Sig. 4 Fase $\quad=0,065>\alpha=0,05$

Karena nilai Sig. 2 fase dan 4 fase $>$ a maka keputusannya menerima HO dan berdistribusi normal.

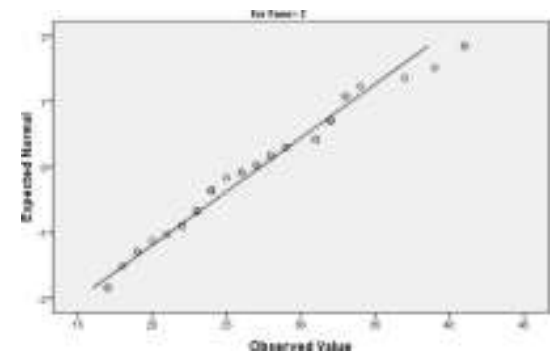

Grafik 2 fase

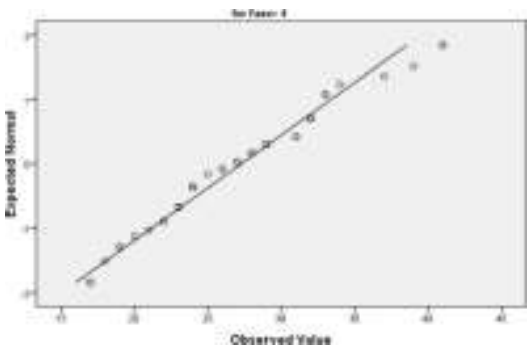

Grafik 4 fase

Gambar 7. Gambar Grafik Q - Q Uji Normalitas 
Jika dilihat sekilas dari grafik Normal $Q-Q$ plot maka garis diagonal dalam grafik ini menggambarkan keadaan ideal dari data yang mengikuti distribusi normal. Titik - titik di sekitar garis adalah keadaan data yang di uji. Jika kebanyakan titik - titik berada sangat dekat dengan garis atau bahkan menempel pada garis, maka dapat disimpulkan bahwa data tersebut mengikuti distribusi normal.

\section{Uji Linieritas}

Uji linieritas bertujuan untuk mengetahui apakah dua variabel mempunyai hubungan yang linear atau tidak secara signifikan. Uji ini biasanya digunakan sebagai prasyarat dalam analisis korelasi atau regresi linear. Dasar pengambilan keputusan dalam uji linearitas adalah:

1. Jika nilai probabilitas $>0,05$ maka hubungan antara variabel $\mathrm{X}$ dengan $\mathrm{Y}$ adalah linear

2. Jika nilai probabilitas $<0,05$ maka hubungan antara variabel $X$ dengan $Y$ adalah tidak linear

\begin{tabular}{|c|c|c|c|c|c|c|c|}
\hline \multicolumn{8}{|c|}{ ANOVA Table } \\
\hline & & & $\begin{array}{l}\text { Sum of } \\
\text { Squares }\end{array}$ & df & Mean Square & $\mathrm{F}$ & Sig. \\
\hline \multirow[t]{5}{*}{ Fase 4 *Fase2 } & Between Groups & (Combined) & 638.688 & 19 & 33.615 & 1.027 & 468 \\
\hline & & Linearity & 17.616 & 1 & 17.616 & .538 & .470 \\
\hline & & Deviation from Linearity & 621.072 & 18 & 34.504 & 1.054 & .443 \\
\hline & Within Groups & & 818.512 & 25 & 32.740 & & \\
\hline & Total & & 1457.200 & 44 & & & \\
\hline
\end{tabular}

Gambar 8. Hasil Uji Linieritas dengan SPSS

16.0 Berdasarkan analisis diatas dapat di jelaskan sebagai berikut

1. Hipotesis

$\mathrm{HO}=$ Terdapat Hubungan antara Fase 2 dan Fase 4

$\mathrm{H} 1$ = Tidak terdapat hubungan antara Fase 2 dan Fase 4

2. Tingkat

Signifikansi $\alpha=$

$5 \%$

3. Daerah kritis

Jika Signifikan $\leq \alpha$ : Tolak HO

4. Statistik Uji

Sig. tabel $=0,443>\alpha=0,05$

Karena nilai Sig. tabel > 0,05 maka HO diterima dan dapat disimpulkan bahwa antara fase 2 dengan fase 4 memiliki hubungan yang linier.

\section{Hipotesis}

Setelah dilakukannya uji normalitas dan linieritas, selanjutnya dilakukan uji dependen sample $\mathrm{T}$ test. Karena dalam penelitian ini akan membandingkan perilaku menunggu pengguna sepeda motor pasa simpang yang memiliki jenis fase yang berbeda yaitu 2 fase dan 4 fase serta dengan menggunakan sample yang sama. 
1. Hipotesis

$\mathrm{HO}=$ Tidak terdapat perbedaan yang signifikan antara perilaku menunggu pada fase 2 dan fase 4

$\mathrm{H} 1$ = Terdapat perbedaan yang signifikan antara perilaku menunggu pada fase 2 dan fase 4

2. Tingkat

Signifikansi $\alpha=$

$5 \%$

3. Daerah kritis

Jika Signifikan $\leq \alpha$ : Tolak HO
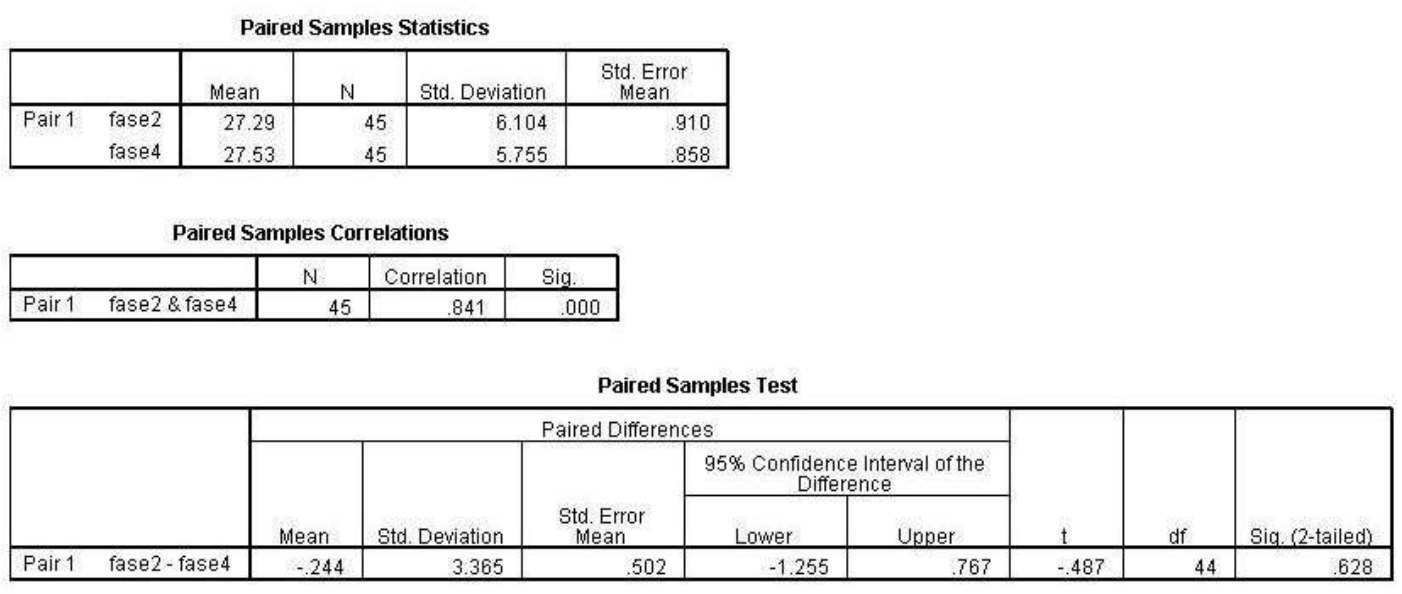

Gambar 8. Hasil Uji Dependen Sample T Test dengan SPSS 16.0

4. Statistik Uji

Sig. (2-tailed) $=0,628>\alpha=0,05$

Berdasarkan nilai uji sig. (2-tailed) sebesar 0,628 > 0,05 maka dapat disimpulkan bahwa tidak terdapat perbedaan yang signifikan antara perilaku menunggu pada fase 2 dan fase 4 yang artinya apabila pengaturan simpang dilakukan memperbanyak jumlah fase tidak berpengaruh untuk mengurangi tingkat agresive driving pada saat menunggu di simpang berapill.

\section{Rekomendasi}

Agar dapat mengurangi tingkat agresive driving pengendara sepeda motor pada saat menunggu di persimpangan berapill, dapat dilakukan dengan beberapa cara :

1. Mendesain simpang dengan menyediakan ruang tunggu khusus sepeda motor pada masing - masing lengan simpang.

2. melakukan perhitungan ulang waktu siklus pada apill agar lebih optimal

3. Memberlakukan early start dan late start pada simmpang yang memiliki 2 fase

\section{KESIMPULAN}

Berdasarkan hasil uji hipotesis, dapat disimpulkan bahwa tidak terdapat perbedaan yang signifikan antara perilaku menunggu pada jenis simpang yang memiliki 2 fase dan 4 fase. 
Hal ini berarti meskipun dilakukan pengaturan simpang dengan memperbanyak jumlah fase tidak berpengaruh terhadap tingkat agresive driving pada saat menunggu di simpang berapill. Meskipun sudah memiliki 4 fase, masih terdapat banyak pelanggaran yang dilakukan oleh pengguna jalan khususnya pengguna sepeda motor.

Selain uji hipotesis juga dapat diketahui tingginya jenis pelanggaran yang dilakukan pengguna sepeda motor pada simpang berapill dengan melakukan observasi langsung di lapangan. Dapat diketahui bahwa jenis pelanggaran yang terjadi pada saat menunggu di simpang adalah berhenti di stop line, berhenti atau menunggu di jalur lain dan lawan arah, berjalan mendahului sebelum lampu apill menyala hijau dengan jumlah pelanggaran yang tertinggi yaitu berhenti atau menunggu di jalur lain dan lawan arah baik pada simpang yang memiliki 2 fase maupun 4 fase.

\section{DAFTAR PUSTAKA}

1993. Peraturan Pemerintah Nomor 43 Tahun 1993 tentang Prasarana dan Lalu Lintas Jalan, Jakarta.

1997. Manual Kapasitas Jalan Indonesia (MKJI), Departemen Pekerjaan Umum Direktorat Jenderal Bina Marga.

Anderson, C.A., \& Bushman, B.J. (2002). Human aggression. Annual Revision Psycology. Journal of psycologi. Vol.53 (27-51).

Houston, J., Harris, P., \& Norman, M. (2003). The aggressive driving behavior scale: Developing a self-report measure of unsafe driving practices. North American Journal of Psychology, 5(2), 269-278.

James, L. \& Nahl, D.(2000). Aggressive diving is Emotionally Impaired Driving: Journal of aggressive driving

Morlok, E.K., ( 1988 ), Pengantar Teknik dan Perencanaan Transportasi, Penerbit Erlangga, Jakarta, Teknik Mesin, Institut Teknologi Bandung, 2008

Sevilla, Consuelo et, Al. 1993. Pengantar Metode Penelitian. Jakarta : Universitas Indonesia Press.

Tasca, Leo.(2000). A review of the literature on aggressive driving research: Ontario Ministry of Transportation Canada. 


\section{LAMPIRAN}

\section{"FORMULIR PENELITIAN" \\ Politeknik Keselamatan Transportasi Jalan}

Tanggal :

\section{Data Pribadi}

1. Nama

2. Jenis Kelamin

3. Usia

4. Pendidikan Terakhir :

5. Alamat

6. Jenis Simpang

\section{Petunjuk Pengisian Angket}

1. Isilah identitas saudara dengan lengkap

2. Silahkan saudara membaca dan memahami setiap pernyataan dalam angket ini. Pilihlah salah satu jawaban yang paling sesuai dengan keadaan diri saudara denga memberikan tanda Centang $(\sqrt{ })$ Pada :

$\begin{array}{llll}\text { SS } & \text { : Sangat Sering } & \text { P } & \text { : Pernah } \\ \text { S } & \text { : Sering } & \text { TP } & \begin{array}{l}\text { : Tidak } \\ \text { Pernah }\end{array} \\ \text { KK } & \text { : Kadang-kadang } & & \end{array}$

3. Dalam Saudara memberikan jawaban, tidak ada jawaban yang salah, semua jawaban benar dan dapat kami terima sesuai dengan keadaan diri saudara yang sebenarnya.

4. Sebelum menjawab bacalah pernyataan di bawah ini dengan cermat dan teliti : 


\begin{tabular}{|c|c|c|c|c|c|c|}
\hline No & $\begin{array}{c}\text { Pernyataa } \\
n\end{array}$ & $\begin{array}{l}\mathrm{S} \\
\mathrm{S}\end{array}$ & $S$ & KK & $P$ & TP \\
\hline 1 & $\begin{array}{l}\text { Saya menunggu lampu Apill menyala hijau } \\
\text { terlebih } \\
\text { dahulu kemudian saya berjalan }\end{array}$ & & & & & \\
\hline 2 & $\begin{array}{l}\text { Saya tetap berjalan dan menambah kecepatan } \\
\text { ketika } \\
\text { lampu Apill menyala merah }\end{array}$ & & & & & \\
\hline 3 & $\begin{array}{l}\text { Saya tidak membunyikan klakson ketika sedang } \\
\text { menunggu antrian pada saat lampu menyala } \\
\text { hijau }\end{array}$ & & & & & \\
\hline 4 & $\begin{array}{l}\text { Saya berjalan pada saat lampu Apill belum } \\
\text { menyala } \\
\text { hijau }\end{array}$ & & & & & \\
\hline 5 & $\begin{array}{l}\text { Saya mengurangi kecepatan dan berhenti ketika } \\
\text { lampu Apill menyala kuning dan hendak } \\
\text { menyala merah }\end{array}$ & & & & & \\
\hline 6 & $\begin{array}{l}\text { Saya menyalakan lampu sein ketika hendak } \\
\text { membelok }\end{array}$ & & & & & \\
\hline 7 & $\begin{array}{l}\text { Posisi kendaraan saya pada saat menunggu di } \\
\text { Apill } \\
\text { berada melebihi garis henti pada Zebra cross }\end{array}$ & & & & & \\
\hline 8 & $\begin{array}{l}\text { Posisi kendaraan saya pada saat menunggu } \\
\text { berada } \\
\text { pada jalur yang benar dan tidak melebihi } \\
\text { batas marka tengah jalan }\end{array}$ & & & & & \\
\hline 9 & $\begin{array}{l}\text { Saya tidak menyalakan lampu sein ketika } \\
\text { hendak } \\
\text { membelok }\end{array}$ & & & & & \\
\hline 10 & $\begin{array}{l}\text { Posisi kendaraan saya saat menunggu di APILL } \\
\text { berada pada lajur tunggu belok kiri }\end{array}$ & & & & & \\
\hline 11 & $\begin{array}{l}\text { Saya Membunyikan klakson ketika sedang } \\
\text { menunggu antrian pada saan lampu APILL } \\
\text { menyala hijau }\end{array}$ & & & & & \\
\hline 12 & $\begin{array}{l}\text { Posisi kendaraan saya pada saat menunggu } \\
\text { berada pada jalur yang benar dan tidak } \\
\text { melebihi batas } \\
\text { marka tengah jalan }\end{array}$ & & & & & \\
\hline 13 & $\begin{array}{l}\text { Posisi kendaraan saya pada saat menunggu di } \\
\text { APILL tidak melebihi zebra cross }\end{array}$ & & & & & \\
\hline
\end{tabular}

